\title{
Comorbidity in patients with branch retinal vein occlusion: case-control study
}

\author{
(c) $\frac{(1) \&(8)}{\mathrm{EY}}$ OPEN ACCESS
}

\author{
Mette Bertelsen medical doctor, clinical research fellow ${ }^{123}$, Allan Linneberg senior researcher and \\ head of department ${ }^{4}$, Thomas Rosenberg consultant ophthalmologist ${ }^{23}$, Nynne Christoffersen \\ consultant ophthalmologist ${ }^{2}$, Henrik Vorum professor of ophthalmology ${ }^{5}$, Else Gade ophthalmologist ${ }^{6}$, \\ Michael Larsen professor of ophthalmology ${ }^{123}$
}

${ }^{1}$ Department of Ophthalmology, Glostrup Hospital, Nordre Ringvej 57, 2600 Glostrup, Denmark; ${ }^{2}$ National Eye Clinic for the Visually Impaired, Kennedy Center, Gl. Landevej 7, 2600 Glostrup; ${ }^{3}$ Faculty of Health and Medical Sciences, University of Copenhagen, Blegdamsvej 3B, Copenhagen, Denmark; ${ }^{4}$ Research Centre for Prevention and Health, Glostrup Hospital, Glostrup; ${ }^{5}$ Department of Ophthalmology, Aalborg University Hospital, Aalborg, Denmark; ${ }^{6}$ Department of Ophthalmology, Odense University Hospital, Odense, Denmark

\begin{abstract}
Objectives To evaluate comorbidity before and after the diagnosis of branch retinal vein occlusion to determine whether it is a consequence of arterial thickening and therefore could serve as a diagnostic marker for other comorbidities and to evaluate the risk factors for the development of such occlusion.

Design Case-control study with prospective follow-up data from Danish national registries.

Setting Four secondary referral centres covering about $80 \%$ of the Danish population (4.4 million).

Participants 1168 patients with photographically verified branch retinal vein occlusion and 116800 controls alive and aged $\geq 40$ when the occlusion was diagnosed in the corresponding case.

Main outcome measures The risk of comorbidity 10 years and 1 year before the diagnosis of branch retinal vein occlusion and the incident comorbidity in a mean period of seven years after the diagnosis, with odds ratios and incidence rate ratios adjusted for age, sex, and year of diagnosis.

Results Risk factors present 10 years and 1 year before the diagnosis of branch retinal vein occlusion included peripheral artery disease (odds ratio $1.83,95 \%$ confidence interval 1.14 to 2.95$)$, diabetes $(1.74,1.40$ to 2.17$)$ and arterial hypertension $(2.16,1.86$ to 2.51$)$. After the diagnosis, patients had an increased risk of developing arterial hypertension (incidence rate ratio $1.37,95 \%$ confidence interval 1.15 to 1.57 ), diabetes (1.51, 1.17 to 2.04$)$, congestive heart failure $(1.41,1.12$ to 1.68$)$, and cerebrovascular disease $(1.49,1.27$ to 1.76$)$.

Conclusion Diabetes, hypertension, and peripheral artery disease are associated with an increased risk of developing branch retinal vein occlusion up to a decade later. Branch retinal vein occlusion was associated with an increased risk of subsequently developing
\end{abstract}

hypertension, diabetes, congestive heart failure, and cerebrovascular disease, emphasising the importance of preventive initiatives. These results fit the assumption that branch retinal vein occlusion is a consequence of arterial thickening and that the arteriovenous crossing signs that precede it are hallmarks of arterial disease.

\section{Introduction}

Branch retinal vein occlusion is a common retinal vascular disorder and a common cause of visual loss in middle aged and elderly people. ${ }^{1}$ Pooled data from population based studies suggest that about 13.9 million adults are affected globally, ${ }^{2}$ and the 15 year incidence rate has been estimated to be $1.8 \% .^{3}$ The clinical manifestations are related to congestion, haemorrhage, ischaemia, and oedema upstream of the site of venous occlusion. ${ }^{1}$ The mechanism of vein occlusion, which occurs where a retinal artery crosses the affected vein, seems to be compression of the vein by a thickened retinal artery (figure $\Downarrow$ ). Because thrombosis is involved, branch retinal vein occlusion is thought to be related not only to peripheral artery disease but also to procoagulant disorders.

Risk factors for branch retinal vein occlusion that have been documented in previous clinical and epidemiological studies include arterial hypertension, ${ }^{4-7}$ diabetes mellitus, ${ }^{47}$ smoking, ${ }^{7}$ high body mass index (BMI), ${ }^{4}$ hypermetropia, ${ }^{8}{ }^{9}$ high intraocular pressure,${ }^{10}$ hyperhomocysteinaemia,,${ }^{11-13}$ deficiency in the protein C pathway, ${ }^{14}$ high $\alpha_{2}$ globulin concentrations, ${ }^{4}$ higher activated factor VII concentrations, ${ }^{15}$ and high blood viscosity. ${ }^{16}$ Not all of these associations have been consistently reproduced. Despite these associated comorbidities and a reported greater risk of cardiovascular disease, ${ }^{17}$ mortality rates of patients with branch retinal vein occlusion have been shown to be comparable with 
those of background populations. ${ }^{18}$ Some studies have shown an association between retinal vein occlusion (including both central and branch occlusion) and increased incidence rates of cerebrovascular disease in patients of all ages ${ }^{19}$ and with cardiovascular disease in patients under the age of $70 .{ }^{20}$ Other studies have reported normal incidence rates of stroke and myocardial infarction in patients with retinal vein occlusion. ${ }^{21} 22$ We cannot assume that central and branch retinal vein occlusion to have common risk factors. In this study, we examined levels of comorbidity before and after the diagnosis of branch retinal vein occlusion, verified with fundus photography, compared with the general population. We assessed the relative contributions of arterial and venous disease to the risk of developing branch retinal vein occlusion and the relative risks of arterial and venous events after presentation.

\section{Methods}

This was as a case-control study with prospective follow-up data from four secondary referral centres in Denmark (the ophthalmology departments at Aalborg, Odense, Glostrup, and Rigshospitalet) between 1976 and 2010 and reference data from the background population. The four referral centres cover an estimated $80 \%$ of diagnosis and treatment of retinal vein occlusion in Denmark. The study hypothesis, that branch retinal vein occlusion is associated with cardiovascular disorders and increased comorbidity that can be broken into arterial and venous components, arose before inspection of the anonymised data.

\section{Inclusion criteria}

We reviewed fundus photographs, fluorescein angiograms, and written records from patients examined and registered at the participating institutions with the diagnosis of branch retinal vein occlusion (ICD-10 (international classification of disease, 10th revision) code H.348) using the following criteria: branch retinal vein compression at an arteriovenous crossing outside the optic disc, upstream venous congestion, intraretinal haemorrhage, oedema, cotton wool spots, and vein-to-vein collaterals with adjacent branch veins in the absence of similar changes in the surrounding venous drainage units. In longstanding cases we accepted the absence of congestion, oedema, and haemorrhage if there were chronic changes such as fibrosis of the occluded branch vein near the site of occlusion. The concomitant finding of diabetic or non-diabetic microvascular retinopathy was accepted if present in both eyes. ${ }^{23}$ Patients with more than one branch retinal vein occlusion were enrolled on the basis of their first occlusion.

As controls, Statistics Denmark sampled people in the general population from the Danish Civil Registration System, which maintains vital information on all residents in Denmark from 1968 and later under unique personal identification numbers. ${ }^{24}$ All deaths in Denmark are recorded in this registry within two weeks. One hundred unduplicated controls per case (116 800 in total) were alive and aged $\geq 40$ on the date of diagnosis in the corresponding case. As all cases and the selected controls were alive at the time of diagnosis of each corresponding case, the controls are set to enter the study at the same time as their corresponding case. Controls were not matched to cases by age, sex, or any other parameter. Socioeconomic data were extracted from the general data inventory of Statistics Denmark.

\section{Comorbidity data}

Comorbidity data for affected patients and controls were assessed with data from the Danish National Patient Registry and the Registry of Medicinal Product Statistics (RMPS). Established in 1977, the patient registry covers all private and public hospital admissions in Denmark and related diagnoses, using ICD-8 before 1995 and ICD-10 from $1995 .{ }^{25}$ From 1995 the Registry of Medicinal Product Statistics has recorded all dispensing of prescription drugs at pharmacies in Denmark by civil registration number, date, and type of drug (Anatomic Therapeutical Chemical (ATC) classification code). ${ }^{26}$

We classified chronic conditions using hospital discharge diagnoses and drug prescriptions (for example, hypertension was assigned if use of antihypertensive drugs was registered) and based isolated events on hospital discharge diagnoses only (for example, stroke was assigned if a discharge diagnosis of stroke had been registered). All data were linked by personal identification numbers, anonymised, and analysed with SAS (version 9.2, SAS Institute, Cary, NC) on terminals linked to Statistics Denmark.

\section{Study period}

We obtained survival and migration status up to 31 December 2010 from the Danish Civil Registration System. Comorbidity data, also obtained by 31 December 2010, were available from 1968 (Danish Civil Registration System), 1977 (Danish National Patient Registry), and 1994 (Registry of Medicinal Product Statistics) and onwards. We defined three periods of assessment for each patient: a 10 year period before the date of diagnosis; a one year period before the date of diagnosis; and the period after diagnosis, from the date of diagnosis to the date of censoring. Patients were censored at the first occurrence of an event other than branch retinal vein occlusion, at the date of their death, or at the end of follow-up on 31 December 2010, whichever came first. Only patients with a complete set of registry data for a given period were included in the analysis of that period. Analysis of the period after the diagnosis excluded individuals who had a given diagnosis before the diagnosis of branch retinal vein occlusion (for example, when we analysed the incidence rate ratio of myocardial infarction after branch retinal vein occlusion, we deleted all individuals with a previous diagnosis of myocardial infarction).

\section{Statistics}

For each patient and each control, information on diagnosis, date of birth, sex, index date, age at index date, observation time, and outcome events were recorded. We carried out systematic testing of our dataset to find any missing data and extreme values. No extreme values were found but missing data were found for the socioeconomic variables with 20 missing income variables and 25308 missing education variables. The missing data, however, were missing at random and found in equal proportions in cases and controls. To ensure that the missing education data did not have any impact on the analysis, we placed observations with missing data in a new category called unknown. Deletion of missing data was found not to influence the estimates. No data were deleted or added to the dataset.

The pooled population was divided into five age groups according to the age of participants at the index date: $<50,50-59$, $60-69,70-79$, and $>80$. We used logistic regression to estimate the risk of branch retinal vein occlusion among the age groups, with the youngest age group as reference. Disposable income at the year of diagnosis was adjusted for inflation and divided 
into quarters. Employment status at the index date was classified as employed, out of work, or retired. The level of education was based on highest attained education at the time of diagnosis and was categorised into short (seven or nine years of mandatory primary school education for patients born before or after 1958, respectively), medium (eight or 10-12 years, completion of final primary school level, secondary school, or vocational education), and higher ( $\geq 12$ years of education). We used logistic regression, adjusted for age at the index date, sex, and index year as categorical variables, to examine differences between patients and controls in terms of socioeconomic characteristics to evaluate whether these characteristics served as significant confounders.

We use the Charlson comorbidity index to summarise the participant's general health status in the 10 year period before the index date. This index takes into account 19 comorbid conditions, scoring each from one to six, based on their associated mortality risk. ${ }^{27}$ The comorbid conditions were assessed from the ICD-8, ICD-10, and ATC codes and used to calculate an index score for each patient and each control. ${ }^{28} 29$

Risk factors during the 10 year and one year periods before the diagnosis of branch retinal vein occlusion were estimated with logistic regression analysis to calculate odds ratios and $95 \%$ confidence intervals for each potential risk factor. The odds ratios were adjusted for age group at the index date, sex, and index year as categorical variables. Adjustments for socioeconomic parameters, including income, employment, and highest education, did not affect the results and were not included in the final model. No interactions were identified by systematic testing.

The relative risks of developing cardiovascular disease and related disorders after the diagnosis were evaluated by excluding participants who had a given diagnosis before developing branch retinal vein occlusion. Incidence rate ratios and 95\% confidence intervals were calculated as hazard ratios obtained from the Cox proportional hazard regression analysis. Initially, models were constructed with all covariates considered to be of potential influence. In the final model the hazard ratios were adjusted only by sex and index year as categorical variables, with age as the underlying time scale, as these were the significant confounders. No interactions were identified by systematic testing.

The risk of mortality in patients with branch retinal vein occlusion compared with controls was estimated by hazard ratios and $95 \%$ confidence intervals obtained from the Cox proportional hazard regression analysis, with age as the underlying time scale adjusted for sex and index year.

\section{Results}

Of the 1168 patients with a photographically verified diagnosis of branch retinal vein occlusion most were aged 60-80 when they received the diagnosis. Of the 116800 controls most were aged 40-70 on the index date. The odds of developing branch retinal vein occlusion increased significantly with age, peaking in the 70-79 age group. There were about equal proportions of men and women in patients and controls (table $1 \Downarrow$ ). There were no significant differences in the socioeconomic characteristics between patients and controls after we adjusted for age, index year, and sex. Hence, the socioeconomic characteristics did not seem to be significant confounders.

In an age and sex adjusted multivariate logistic regression analysis of risk factors present in the periods of 10 years and one year before the diagnosis, peripheral artery disease (odds ratio $1.83,1.14$ to 2.95$)$, arterial hypertension $(2.16,1.86$ to
$2.51)$, and diabetes $(1.74,1.40$ to 2.17$)$ were significant risk factors for the development of branch retinal vein occlusion (table $2 \Downarrow$ ). We found no significant effects for myocardial infarction, cerebrovascular disease, renal disease, use of oral contraceptives, or use of migraine drugs, including separate analyses of ergot alkaloids and triptans.

The mean follow-up after the diagnosis of branch retinal vein occlusion was 7.0 years (SD 6.5 years). Multiple adjusted incidence rate ratios for the risk of developing a condition after the diagnosis were higher (table $3 \Downarrow$ ), including the incidence of arterial hypertension (incidence rate ratio $1.37,1.15$ to 1.57 ), diabetes $(1.51,1.17$ to 2.04$)$, congestive heart failure $(1.41,1.12$ to 1.68$)$, and cerebrovascular disease $(1.49,1.27$ to 1.76$)$. There was no significantly increased risk of developing ischaemic heart disease or myocardial infarction after the diagnosis.

In a Cox regression model, adjusted for sex and year of diagnosis and with age as the underlying time scale, the mortality was not increased in patients with branch retinal vein occlusion (hazard ratio $0.94,0.85$ to $1.05 ; \mathrm{P}=0.30$ ) compared with controls.

\section{Discussion}

In this hospital based study of comorbidity in patients with branch retinal vein occlusion verified with fundus photography over a mean period of 17 years, we found that the risk of developing branch retinal vein occlusion increased prominently with age, reaching its highest level in people aged 70-79. Before the diagnosis of branch retinal vein occlusion, people who would eventually develop this condition had higher overall comorbidity, and hypertension, diabetes, and peripheral artery disease were more prevalent than in the background population. After receiving a diagnosis, patients without a history of these disorders were more likely than the background population to develop arterial hypertension, diabetes, congestive heart failure, and cerebrovascular disease, and their overall burden of disease was increased.

\section{Comparison with other studies}

Our findings are consistent with those from a recent cohort study based on healthcare claims databases from the United States. The study reported an increased incidence rate (incidence rate ratio $1.72,95 \%$ confidence interval 1.27 to 2.34 ) of cerebrovascular disease and a higher comorbidity index in patients with retinal vein occlusion compared with the general population. ${ }^{19}$ It also reported that the event rates for myocardial infarction were similar in patients with retinal vein occlusion and controls. The conclusion persisted after a subgroup analysis was performed for people with branch retinal vein occlusion and central retinal vein occlusion.

Studies from Taiwan found that retinal vein occlusion was not independently associated with an increased risk of acute myocardial infarction, and an association between incident stroke and retinal vein occlusion was found only in the subgroup of patients aged 60-69. ${ }^{21} 22$ Other follow-up studies with fewer observations have found less consistent results, including both the presence and the absence of correlations between myocardial infarction and cerebrovascular disease..$^{20} 3031$

The risk factors identified in the current study related to the development of branch retinal vein occlusion included diabetes and hypertension, which have also been consistently identified in cross sectional ${ }^{32-35}$ and follow-up ${ }^{4-7} 3031$ studies. Previously reported risk factors from cross sectional studies that were not identified in this study include coronary artery disease ${ }^{32}$ and kidney disease. ${ }^{34}$ 
Coagulation characteristics have been investigated for their potential involvement in retinal vein occlusion, and reported associations have linked retinal vein occlusion to hyperhomocysteinaemia, ${ }^{11-13}$ deficiency in the protein $\mathrm{C}$ pathway, ${ }^{14}$ high $\alpha_{2}$ globulin concentrations, ${ }^{4}$ higher activated factor VII concentrations, ${ }^{15}$ and increased blood viscosity. ${ }^{16} \mathrm{~A}$ meta-analysis of 26 studies suggested that only hyperhomocysteinaemia and anticardiolipin antibody concentrations were significantly independently associated with retinal vein occlusion, ${ }^{36}$ while another meta-analysis supported an effect of hyperhomocysteinaemia. ${ }^{37}$ Studies of specific risk factors for branch retinal vein occlusion, however, have found an association only with higher concentrations of activated factor VII in patients of all ages ${ }^{15}$ and factor XII deficiency in patients aged $\leq 45 .{ }^{38}$ Other studies of specific risk factors found no associations with thrombophilia. ${ }^{39}{ }^{40}$ In the present study, only a single patient with branch retinal vein occlusion out of 1168 had been registered with a diagnosis of hypercoagulability within 10 years before the diagnosis. Thus, our results indicate that the contribution of clinically apparent hypercoagulability disorders to branch retinal vein occlusion is small at an epidemiological level. We cannot, however, exclude the possibility that hypercoagulability can contribute in individual cases.

We also found peripheral artery disease to be a risk factor for incident branch retinal vein occlusion, whereas peripheral venous disease was not. This observation supports previous findings that branch retinal vein occlusion is a consequence of arteriolar wall thickening. To the best of our knowledge, this is the first study to report peripheral artery disease as an isolated risk factor. ${ }^{41}$

An association between migraine and branch retinal vein occlusion has previously been reported. ${ }^{3}$ In our study the use of migraine drugs, including ergot alkaloids and triptans, had no detectable effect on its development. Our study was limited, however, by being based on hospital records, meaning that patients with a diagnosis of migraine in primary care could be identified only if they used prescription drugs that are specific for migraine.

In contrast with earlier studies that found oral contraceptives to be a risk factor for retinal vein occlusion, ${ }^{42}$ we found no such association. Our patients, however, were generally older than the typical user of oral contraceptives and hence the study was not ideally suited to examine this issue. ${ }^{43}$

We found no significant difference in mortality between patients with branch retinal vein occlusion and controls, despite the association we found between branch retinal vein occlusion and cardiovascular comorbidities. This is comparable with previous studies of mortality risk in patients with branch retinal vein occlusion, ${ }^{18} 2031$ in which the 329 patients in the Danish paper by Christoffersen and colleagues, ${ }^{18}$ are a subset of the 1168 patients in the present study. Several explanations for this apparent contradiction have been proposed, including a survival effect of the participants who survived with arterial wall thickening to develop branch retinal vein occlusion and the effect of interventions against cardiovascular risk factors prompted by the occlusion. Hypothetically, thickening of the arterial wall in arteries such as those of the retina, which have a typical lumen diameter of $100 \mu \mathrm{m}$, can also help reduce the transmission of high arterial blood pressure to the capillary bed and thus protect against microangiopathy.

\section{Strengths and limitations of the study}

Many previous comorbidity studies were small retrospective case series ${ }^{2030}$ or case-control studies without a well defined follow-up period ${ }^{40} 30323435$ and where photographic verification was often not available. ${ }^{192122}$ Additionally, many studies made no distinction between branch and central retinal vein occlusion, ${ }^{6} 20-22313235$ although the two have long been known to have different risk factors. ${ }^{334}$ The main strength our study, which is among the largest performed to date, was that it had access to systemically collected health data recorded in well defined study periods before and after the diagnosis for both cases and the background population. Furthermore, the diagnosis was verified in all cases by reviewing fundus photographic records.

The hospital based diagnoses of branch retinal vein occlusion in this study might have conferred a selection bias in favour of the enrolment of more symptomatic cases, patients most likely to respond to treatment, and patients without other health problems that might deter them from seeking care for poor vision. Specifically, we are likely to have missed peripheral and small macular branch retinal vein occlusions, which are often asymptomatic. We must therefore assume that our study, has a relative over-representation of fovea involving cystoid macular oedema, which is the main cause of visual impairment in patients with branch retinal vein occlusion. ${ }^{41}$ These biases could have led to conclusions that differ from those of population based studies. Asymptomatic cases were included in the study, however, as a result of incidental findings made during examination for other ocular disorders.

Diabetic retinopathy makes the diagnosis of branch retinal vein occlusion more challenging. Hence, we chose to exclude cases in which no clear diagnosis could be made. This could potentially have biased our study towards identifying a lower impact level for diabetes as a risk factor.

We assessed comorbidity using registry data, which made the analysis vulnerable to misclassifications and missing data. Systematic testing of our dataset, however, suggests that potential errors were found in equal proportions in cases and controls, and all missing data were found to be missing at random. Validation studies of Danish national registries have previously been published. ${ }^{24-26}$

\section{Conclusions}

Our study supports the theory that branch retinal vein occlusion is a marker of progressive cardiovascular disease that should be included in the risk assessment of patients for preventive intervention. General practitioners play an important role in the medical management of branch retinal vein occlusion through the identification and management of modifiable risk factors. Our study supports the importance of following the guidelines for medical management suggested by the Royal College of Ophthalmologists and discussed in a recent review of management of retinal vein occlusion. ${ }^{45}$ Investigations and interventions prompted by the diagnosis of branch retinal vein occlusion should focus on arterial hypertension, hyperlipidaemia, and diabetes. The condition in itself does not warrant anticoagulant treatment.

We acknowledge the support of the Danish Diabetes Academy. Contributors: $M B$ and $M L$ developed the study design. $M B, M L, A L$, and TR analysed the data and drafted the manuscript. MB, NC, HV, ML, and EG contributed to the data collection. All authors contributed to the interpretation of the data and revision of the manuscript. MB is guarantor. Funding: This study was funded by the Dag Lenards Foundation. The foundation had no role in the study design; in the collection, analysis, and interpretation of data; in the writing of the reports; or in the decision to submit the article for publication. 


\section{What is already known on this topic}

Branch retinal vein occlusion has been inconsistently associated with diabetes and cardiovascular disease, including arterial hypertension Many previous comorbidity studies have had conflicting results and varied widely with regards to study design, population size, and photographic verification of the diagnosis, and have not always distinguished between branch and central retinal vein occlusion

\section{What this study adds}

This large study assessed comorbidity before and after the diagnosis of photographically verified branch retinal vein occlusion Risk factors for incident branch retinal vein occlusion were hypertension, diabetes, peripheral artery disease, and increasing age The comorbidities that developed after diagnosis were dominated by the same conditions plus congestive heart failure and cerebrovascular disease

The results fit the assumption that branch retinal vein occlusion is a consequence of arterial wall thickening and supports that endothelial damage caused by shear stress at arteriovenous crossings where the retinal veins are compressed is more important than a prothrombotic disposition

Competing interests: All authors have completed the ICMJE uniform disclosure form at www.icmje.org/coi_disclosure.pdf (available on request from the corresponding author) and declare: no support from any organisation for the submitted work; no financial relationships with any organisations that might have an interest in the submitted work in the previous three years; no other relationships or activities that could appear to have influenced the submitted work.

Ethical approval: Not required.

Data sharing: No additional data available.

1 Rehak J, Rehak M. Branch retinal vein occlusion: pathogenesis, visual prognosis, and treatment modalities. Curr Eye Res 2008;33:111-31.

2 Rogers S, McIntosh RL, Cheung N, Lim L, Wang JJ, Mitchell P, et al. The prevalence of retinal vein occlusion: pooled data from population studies from the United States, Europe, Asia, and Australia. Ophthalmology 2010;117:313-9.

3 Klein R, Moss SE, Meuer SM, Klein BE. The 15-year cumulative incidence of retinal vein occlusion: the Beaver Dam Eye Study. Arch Ophthalmol 2008;126:513-8.

4 Eve Disease Case-Control Study Group. Risk factors for branch retinal vein occlusion. Am J Ophthalmol 1993;116:286-96.

5 Johnston RL, Brucker AJ, Steinmann W, Hoffman ME, Holmes JH. Risk factors of branch retinal vein occlusion. Arch Ophthalmol 1985;103:1831-2.

6 Rath EZ, Frank RN, Shin DH, Kim C. Risk factors for retinal vein occlusions. A case-control study. Ophthalmology 1992;99:509-14.

7 Klein R, Klein BE, Moss SE, Meuer SM. The epidemiology of retinal vein occlusion: the Beaver Dam Eye Study. Trans Am Ophthalmol Soc 2000;98:133-41.

8 Ariturk N, Oge Y, Erkan D, Sullu Y, Mohajery F. Relation between retinal vein occlusions and axial length. Br J Ophthalmol 1996;80:633-6.

9 Majji AB, Janarthanan M, Naduvilath TJ. Significance of refractive status in branch retinal vein occlusion. A case-control study. Retina 1997;17:200-4

10 Frucht J, Shapiro A, Merin S. Intraocular pressure in retinal vein occlusion. Br J Ophthalmol 1984;68:26-8.

11 Singer DR, Hasan K. Homocysteine and other new risk factors for central retinal vein occlusion: new challenges for the internal medicine physician. Eur J Intern Med 2002;13:160-2.

12 Cahill M, Karabatzaki M, Meleady R, Refsum H, Ueland P, Shields D, et al. Raised plasma homocysteine as a risk factor for retinal vascular occlusive disease. Br J Ophthalmol 2000;84:154-7.

13 Chua B, Kifley A, Wong TY, Mitchell P. Homocysteine and retinal vein occlusion: a population-based study. Am J Ophthalmol 2005;139:181-2.

14 Greiner K, Hafner G, Dick B, Peetz D, Prellwitz W, Pfeiffer N. Retinal vascular occlusion and deficiencies in the protein C pathway. Am J Ophthalmol 1999;128:69-74.

15 Kadayifcilar S, Ozatli D, Ozcebe O, Sener EC. Is activated factor VII associated with retinal vein occlusion? Br J Ophthalmol 2001;85:1174-8.

16 Williamson TH, Rumley A, Lowe GD. Blood viscosity, coagulation, and activated protein $C$ resistance in central retinal vein occlusion: a population controlled study. Br J Ophthalmo 1996;80:203-8.

17 Martin SC, Butcher A, Martin N, Farmer J, Dobson PM, Bartlett WA, et al. Cardiovascular risk assessment in patients with retinal vein occlusion. Br J Ophthalmol 2002;86:774-6.

18 Christoffersen N, Gade E, Knudsen L, Juel K, Larsen M. Mortality in patients with branch retinal vein occlusion. Ophthalmology 2007;114:1186-9.

19 Werther W, Chu L, Holekamp N, Do DV, Rubio RG. Myocardial infarction and cerebrovascular accident in patients with retinal vein occlusion. Arch Ophthalmol 2011;129:326-31

20 Cugati S, Wang JJ, Knudtson MD, Rochtchina E, Klein R, Klein BE, et al. Retinal vein occlusion and vascular mortality: pooled data analysis of 2 population-based cohorts. Ophthalmology 2007:114:520-4

21 Ho JD, Liou SW, Lin HC. Retinal vein occlusion and the risk of stroke development: a five-year follow-up study. Am J Ophthalmol 2009;147:283-90.

$22 \mathrm{Hu}$ CC, Ho JD, Lin HC. Retinal vein occlusion and the risk of acute myocardial infarction (correction of infraction): a 3-year follow-up study. Br J Ophthalmol 2009;93:717-20.

23 Munch IC, Kessel L, Borch-Johnsen K, Glumer C, Lund-Andersen H, Larsen M. Microvascular retinopathy in subjects without diabetes: the Inter99 Eye Study. Acta Ophthalmol 2011;90:613-9.
24 Pedersen $\mathrm{CB}$, Gotzsche $\mathrm{H}$, Moller JO, Mortensen PB. The Danish Civil Registration System. A cohort of eight million persons. Dan Med Bull 2006;53:441-9.

25 Andersen TF, Madsen M, Jorgensen J, Mellemkjoer L, Olsen JH. The Danish nationa hospital register. A valuable source of data for modern health sciences. Dan Med Bull 1999;46:263-8.

26 Kildemoes HW, Sorensen HT, Hallas J. The Danish national prescription registry. Scand J Public Health 2011:39(7 suppl):38-41.

27 Charlson ME, Pompei P, Ales KL, MacKenzie CR. A new method of classifying prognostic comorbidity in longitudinal studies: development and validation. $J$ Chronic Dis 1987;40:373-83

28 Kuo RN, Dong YH, Liu JP, Chang CH, Shau WY, Lai MS. Predicting healthcare utilization using a pharmacy-based metric with the WHO's Anatomic Therapeutic Chemical algorithm. Med Care 2011:49:1031-9.

29 Sundararajan V, Henderson T, Perry C, Muggivan A, Quan H, Ghali WA. New ICD-10 version of the Charlson comorbidity index predicted in-hospital mortality. $J$ Clin Epidemiol 2004:57:1288-94

30 Rubinstein K, Jones EB. Retinal vein occlusion: long-term prospects: 10 years' follow-up of 143 patients. Br J Ophthalmol 1976;60:148-50.

31 Tsaloumas MD, Kirwan J, Vinall H, O'Leary MB, Prior P, Kritzinger EE, et al. Nine year follow-up study of morbidity and mortality in retinal vein occlusion. Eye (Lond) 2000;14:821-7.

32 Lim LL, Cheung N, Wang JJ, Islam FM, Mitchell P, Saw SM, et al. Prevalence and risk factors of retinal vein occlusion in an Asian population. Br J Ophthalmol 2008;92:1316-9.

33 Appiah AP, Trempe CL. Risk factors associated with branch vs. central retinal vein occlusion. Ann Ophthalmol 1989:21:153-7.

34 Cheung N, Klein R, Wang JJ, Cotch MF, Islam AF, Klein BE, et al. Traditional and nove cardiovascular risk factors for retinal vein occlusion: the multiethnic study of atherosclerosis. Invest Ophthalmol Vis Sci 2008;49:4297-302.

35 Yasuda M, Kiyohara Y, Arakawa S, Hata Y, Yonemoto K, Doi Y, et al. Prevalence and systemic risk factors for retinal vein occlusion in a general Japanese population: the Hisayama study. Invest Ophthalmol Vis Sci 2010:51:3205-9.

36 Janssen MC, den HM, Cruysberg JR, Wollersheim H, Bredie SJ. Retinal vein occlusion: a form of venous thrombosis or a complication of atherosclerosis? A meta-analysis of thrombophilic factors. Thromb Haemost 2005;93:1021-6.

37 Cahill MT, Stinnett SS, Fekrat S. Meta-analysis of plasma homocysteine, serum folate, serum vitamin $\mathrm{B}(12)$, and thermolabile MTHFR genotype as risk factors for retinal vascular occlusive disease. Am J Ophthalmol 2003;136:1136-50.

38 Kuhli C, Scharrer I, Koch F, Ohrloff C, Hattenbach LO. Factor XII deficiency: a thrombophilic risk factor for retinal vein occlusion. Am J Ophthalmol 2004;137:459-64.

39 Greiner K, Peetz D, Winkgen A, Prellwitz W, Pfeiffer N, Hafner G. Genetic thrombophilia in patients with retinal vascular occlusion. Int Ophthalmol 1999;23:155-60.

40 Weger M, Renner W, Steinbrugger I, Cichocki L, Temmel W, Stanger O, et al. Role of thrombophilic gene polymorphisms in branch retinal vein occlusion. Ophthalmology 2005;112:1910-5.

41 Wong TY, Scott IU. Clinical practice. Retinal-vein occlusion. N Engl J Med 2010;363:2135-44

42 Kirwan JF, Tsaloumas MD, Vinall H, Prior P, Kritzinger EE, Dodson PM. Sex hormone preparations and retinal vein occlusion. Eye (Lond) 1997;11:53-6.

43 Lidegaard O, Nielsen LH, Skovlund CW, Skjeldestad FE, Lokkegaard E. Risk of venous thromboembolism from use of oral contraceptives containing different progestogens and oestrogen doses: Danish cohort study, 2001-9. BMJ 2011;343:d6423.

44 Hayreh SS, Zimmerman B, McCarthy MJ, Podhajsky P. Systemic diseases associated with various types of retinal vein occlusion. Am J Ophthalmol 2001;131:61-77.

45 Kiire CA, Chong NV. Managing retinal vein occlusion. BMJ 2012;344:e499.

Accepted: 12 November 2012

\section{Cite this as: BMJ 2012;345:e7885}

This is an open-access article distributed under the terms of the Creative Commons Attribution Non-commercial License, which permits use, distribution, and reproduction in any medium, provided the original work is properly cited, the use is non commercial and is otherwise in compliance with the license. See: http://creativecommons.org/licenses/by$\mathrm{nc} / 2.0 /$ and http://creativecommons.org/licenses/by-nc/2.0/legalcode 


\section{Tables}

Table 1/ Characteristics of study population comprising patients with branch retinal vein occlusion (BRVO) and controls from general population. Figures are numbers (percentage) of participants and odds ratios (95\% confidence intervals)

\begin{tabular}{|c|c|c|c|c|c|c|}
\hline & \multirow[b]{2}{*}{ BRVO (n=1168) } & \multirow[b]{2}{*}{ Controls $(n=116800)$} & \multicolumn{2}{|c|}{ Unadjusted } & \multicolumn{2}{|c|}{ Adjusted } \\
\hline & & & Odds ratio $(95 \% \mathrm{Cl})$ & $P$ value & Odds ratio $(95 \% \mathrm{Cl})$ & $P$ value \\
\hline \multicolumn{7}{|l|}{ Age $(\text { years })^{*}$ : } \\
\hline$<50$ & $88(7.5)$ & 35919 (31) & $(1.00)$ & \multirow[t]{5}{*}{$<0.001$} & $(1.00) \dagger$ & \multirow[t]{5}{*}{$<0.001 \dagger$} \\
\hline $50-59$ & $235(20)$ & $31383(27)$ & 3.06 (2.39 to 3.90$)$ & & 3.06 (2.39 to 3.91$) \dagger$ & \\
\hline $60-69$ & 378 (32) & $24627(21)$ & 6.26 (4.96 to 7.90$)$ & & 6.28 (4.98 to 7.93$) \dagger$ & \\
\hline $70-79$ & $330(28)$ & $16323(14)$ & 8.25 (6.52 to 10.45$)$ & & $8.30(6.55$ to 10.50$) \dagger$ & \\
\hline$>80$ & $137(12)$ & $8548(7)$ & 6.54 (4.99 to 8.56$)$ & & 6.60 (5.04 to 8.65$) \dagger$ & \\
\hline Men & $549(47)$ & $55793(48)$ & \multirow[t]{2}{*}{$0.97(0.86$ to 1.09$)$} & \multirow[t]{2}{*}{0.50} & \multirow[t]{2}{*}{0.95 (0.85 to 1.07$) \ddagger$} & \multirow[t]{2}{*}{$0.43 \ddagger$} \\
\hline Women & $619(53)$ & $61007(52)$ & & & & \\
\hline \multicolumn{7}{|c|}{ Income (quarter): } \\
\hline 1 & 577 (49) & $55575(48)$ & \multirow[t]{4}{*}{1.07 (0.97 to 1.20$)$} & \multirow[t]{4}{*}{0.20} & \multirow[t]{4}{*}{$1.08(0.96$ to 1.20$) \S$} & \multirow[t]{4}{*}{$0.18 \S$} \\
\hline 2 & $25(1)$ & $2456(2.1)$ & & & & \\
\hline 3 & $289(25)$ & $29067(25)$ & & & & \\
\hline 4 & $275(24)$ & $29131(25)$ & & & & \\
\hline \multicolumn{7}{|l|}{ Employment: } \\
\hline Employed & $533(52)$ & $54622(53)$ & \multirow[t]{3}{*}{0.95 (0.84 to 1.08$)$} & \multirow[t]{3}{*}{0.49} & \multirow[t]{3}{*}{$0.96(0.85$ to 1.08$) \S$} & \multirow[t]{3}{*}{$0.48 \S$} \\
\hline Unemployed & $24(2)$ & $2279(2.2)$ & & & & \\
\hline Retired & $477(46)$ & $46808(45)$ & & & & \\
\hline \multicolumn{7}{|c|}{ Highest educationף: } \\
\hline Unknown & $257(22)$ & 25051 (22) & \multirow[t]{4}{*}{1.07 (0.97 to 1.19$)$} & \multirow[t]{4}{*}{0.19} & \multirow[t]{4}{*}{$1.06(0.95$ to 1.18$) \S$} & \multirow[t]{4}{*}{$0.23 \S$} \\
\hline Short & 365 (32) & $35556(31)$ & & & & \\
\hline Medium & $384(33)$ & 37855 (33) & & & & \\
\hline Higher & $153(13)$ & $17537(15)$ & & & & \\
\hline
\end{tabular}

*By date of diagnosis in index case.

†Adjusted for sex and index year comparing risk of BRVO among age groups with youngest age group used as reference. P value calculated by trend test. $\ddagger$ Adjusted for age group and index year.

$\S$ Adjusted for age group, sex, and index year. Analysis evaluates associations between socioeconomic status and risk of BRVO.

IShort=7-9 years, medium $=8-12$, higher $=\geq 12$; see text for details. 
Table 2| Risk factors present 10 years and 1 year before diagnosis of branch retinal vein occlusion (BRVO). Figures are numbers (percentage) of participants and odds ratios $(95 \%$ confidence intervals)

\begin{tabular}{|c|c|c|c|c|c|c|c|c|}
\hline & \multicolumn{4}{|c|}{10 year period before BRVO } & \multicolumn{4}{|c|}{1 year period before BRVO } \\
\hline & Cases & Controls & OR $(95 \% \mathrm{Cl})^{\star}$ & $P$ value & Cases & Controls & OR $(95 \% \mathrm{Cl})^{*}$ & $P$ value \\
\hline Myocardial infarction & $42(3.8)$ & $3148(2.8)$ & $0.92(0.67$ to 1.25$)$ & 0.57 & $5(0.4)$ & $518(0.5)$ & $0.62(0.26$ to 1.5$)$ & 0.30 \\
\hline $\begin{array}{l}\text { Congestive heart } \\
\text { failure }\end{array}$ & $24(2.2)$ & $2242(2.0)$ & 0.65 (0.44 to 1.01$)$ & 0.06 & $12(1.0)$ & $542(0.5)$ & $1.10(0.61$ to 2.00$)$ & 0.76 \\
\hline $\begin{array}{l}\text { Peripheral artery } \\
\text { disease }\end{array}$ & $49(4.4)$ & $2297(2.1)$ & $1.43(1.07$ to 1.91$)$ & 0.02 & $18(1.5)$ & $623(0.5)$ & 1.83 (1.14 to 2.95$)$ & 0.009 \\
\hline $\begin{array}{l}\text { Peripheral venous } \\
\text { disease }\end{array}$ & $18(1.6)$ & $1325(1.2)$ & $1.05(0.66$ to 1.68$)$ & 0.83 & $6(0.5)$ & $222(0.2)$ & $1.96(0.87$ to 4.45$)$ & 0.10 \\
\hline $\begin{array}{l}\text { Cerebrovascular } \\
\text { disease }\end{array}$ & $75(6.8)$ & $4583(4.1)$ & $1.08(0.85$ to 1.37$)$ & 0.54 & $23(2.0)$ & $1055(1.0)$ & 1.38 (0.91 to 2.10$)$ & 0.13 \\
\hline Liver disease & $7(0.6)$ & $791(0.7)$ & $0.93(0.44$ to 1.97$)$ & 0.85 & $2(0.2)$ & $91(0.1)$ & $1.62(0.51$ to 5.09$)$ & 0.41 \\
\hline Renal disease & $16(1.4)$ & $832(0.7)$ & $1.42(0.86$ to 2.35$)$ & 0.17 & $7(0.6)$ & $298(0.3)$ & $1.64(0.77$ to 3.49$)$ & 0.20 \\
\hline $\begin{array}{l}\text { Diabetes with end } \\
\text { organ damage }\end{array}$ & $42(3.8)$ & $1547(1.4)$ & 2.04 (1.49 to 2.80$)$ & $<0.001$ & $17(1.5)$ & $508(0.4)$ & 2.45 (1.50 to 4.00$)$ & $<0.001$ \\
\hline $\begin{array}{l}\text { Ischaemic heart } \\
\text { disease }\end{array}$ & $117(11)$ & $7192(6.5)$ & 1.13 (0.93 to 1.38$)$ & 0.20 & $25(2.1)$ & $1731(1.6)$ & 0.95 (0.63 to 1.41$)$ & 0.78 \\
\hline Hypercoagulability & $1(0.1)$ & $75(0.1)$ & - & - & - & - & - & - \\
\hline Diabetes† & $62(13)$ & $3174(6.5)$ & 1.52 (1.16 to 1.99$)$ & 0.002 & $92(11)$ & $4151(4.8)$ & 1.74 (1.40 to 2.17$)$ & $<0.001$ \\
\hline Hypertension† & $351(72)$ & $20445(42)$ & 2.24 (1.81 to 2.77 ) & $<0.001$ & $511(60)$ & $26634(31)$ & 2.16 (1.86 to 2.51$)$ & $<0.001$ \\
\hline $\begin{array}{l}\text { Cardiovascular } \\
\text { disease †‡ }\end{array}$ & $386(79)$ & $26528(54)$ & 2.11 (1.68 to 2.65 ) & $<0.001$ & $531(62)$ & $29433(34)$ & 2.07 (1.79 to 2.40$)$ & $<0.001$ \\
\hline Oral contraceptives§ & $18(3.7)$ & $4008(8.2)$ & $1.56(0.88$ to 2.74$)$ & 0.30 & $2(0.2)$ & $258(0.3)$ & 3.28 (0.79 to 13.61$)$ & 0.11 \\
\hline Migraine drugs§ & $24(4.9)$ & $2318(4.7)$ & 1.42 (0.93 to 2.16$)$ & 0.45 & $11(1.3)$ & $1510(1.8)$ & $1.08(0.59$ to 1.96$)$ & 0.81 \\
\hline $\begin{array}{l}\text { Average Charlson } \\
\text { index }(95 \% \mathrm{Cl}) \dagger\end{array}$ & $\begin{array}{c}0.99(0.90 \text { to } \\
1.09)\end{array}$ & $\begin{array}{c}0.65(0.64 \text { to } \\
0.66)\end{array}$ & 1.21 (1.08 to 1.36$)$ & 0.001 & - & - & - & - \\
\hline
\end{tabular}

*Logistic regression estimating odds ratio (OR) adjusted for age, sex, and index year to evaluate risk factors for BRVO.

†Diagnoses based on both hospital discharge diagnoses and drug prescriptions.

$\ddagger$ Cardiovascular disease includes hypertension, cerebrovascular disease, ischaemic heart disease, congestive heart failure, peripheral vascular disease, and use of cardiovascular drugs.

§Diagnoses based on drug prescriptions only (remaining diagnoses based on hospital discharge diagnoses only). 
Table 3| Risks of incident comorbidity after diagnosis of branch retinal vein occlusion (BRVO). Figures are numbers (percentage) of participants and incidence rate ratios $(95 \%$ confidence intervals)

\begin{tabular}{|c|c|c|c|c|}
\hline & BRVO cases & Controls & IRR $(95 \% \mathrm{CI})^{*}$ & $P$ value \\
\hline Hypertension† & $188(30)$ & $14688(17)$ & 1.37 (1.15 to 1.57$)$ & $<0.001$ \\
\hline Diabetest & $52(5.1)$ & $2976(2.8)$ & 1.51 (1.17 to 2.04$)$ & 0.002 \\
\hline Myocardial infarction & $61(5.7)$ & $3381(3.1)$ & 1.24 (0.97 to 1.62$)$ & 0.10 \\
\hline Congestive heart failure & $96(8.9)$ & $4401(4.0)$ & 1.41 (1.12 to 1.68$)$ & 0.001 \\
\hline Ischaemic heart disease & $123(12)$ & $7532(7.2)$ & $1.21(0.97$ to 1.41$)$ & 0.11 \\
\hline Peripheral artery disease & $63(6.0)$ & $3375(3.1)$ & 1.26 (0.98 to 1.62$)$ & 0.10 \\
\hline Peripheral venous disease & $24(2.2)$ & $1445(1.3)$ & 1.24 (0.83 to 1.86$)$ & 0.30 \\
\hline Cerebrovascular disease & $145(15)$ & $6415(6.0)$ & $1.49(1.27$ to 1.76$)$ & $<0.001$ \\
\hline Cardiovascular disease $\ddagger$ & $197(33)$ & $18184(22)$ & 1.15 (0.99 to 1.32$)$ & 0.07 \\
\hline
\end{tabular}

${ }^{*}$ Cox regression model estimating incidence rate ratio (IRR) with age as underlying timescale adjusted for sex and index year.

†Diagnoses based on hospital discharge diagnoses and drug prescriptions (remaining diagnoses based on hospital discharge diagnoses only).

$\ddagger$ Cardiovascular disease includes hypertension, cerebrovascular disease, ischaemic heart disease, congestive heart failure, peripheral vascular disease, and cardiovascular drugs. 


\section{Figure}

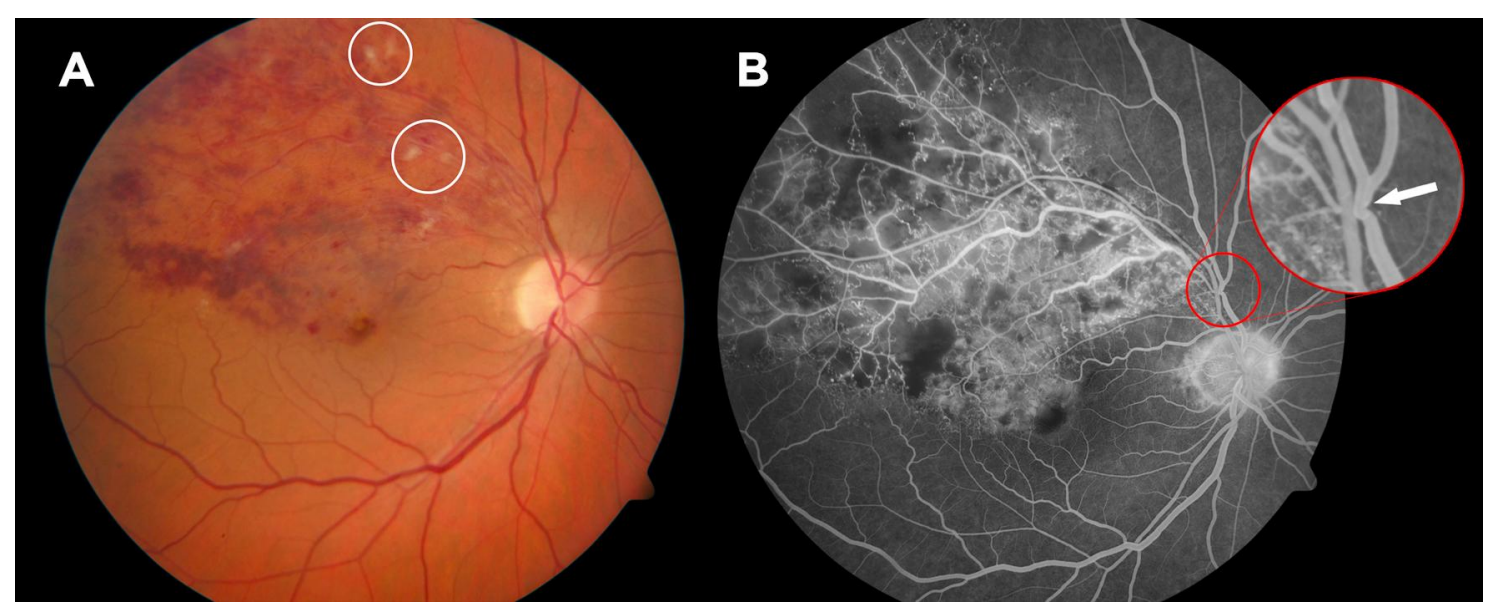

Branch retinal vein occlusion of superotemporal branch vein in the right eye. (A) Fundus photograph showing widespread haemorrhages and axonal congestion (cotton wool spots; white circles) upstream of the venous occlusion and (B) fundus fluorescein late phase angiogram of the same eye showing a notch in a major vein (arrow) at the site where a branch vein drains into a trunk vein and has been compressed and wholly or partially occluded by an artery immediately to the left of the trunk vein. Impaired venous drainage at the site of compression is compensated, to some extent, by collaterals that drain to trunk veins with intact outflow 